(6)

\section{OPEN ACCESS}

- Additional material is published online only. To view please visit the journal online (http://dx.doi.org/10.1136/ archdischild-2013-305267).

Neurodisability Service, Great Ormond, Street Hospital for Children, London, UK

Correspondence to Dr Alison Salt, Neurodisability Service, The Nurses Home Building, Great Ormond, Street Hospital for Children, Great Ormond Street, London WC1N 3JH, UK;

alison.salt@gosh.nhs.uk

Received 20 May 2014 Revised 29 July 2014 Accepted 30 July 2014 Published Online First 27 August 2014

\title{
Common visual problems in children with disability
}

\author{
Alison Salt, Jenefer Sargent
}

\section{ABSTRACT}

Children with disability are at a substantially higher risk of visual impairment (VI) (10.5\% compared with $0.16 \%)$ but also of ocular disorders of all types, including refractive errors and strabismus. The aetiology of VI in children with disability reflects that of the general population and includes cerebral $\mathrm{VI}$, optic atrophy, as well as primary visual disorders such as retinal dystrophies and structural eye anomalies. VI and other potentially correctable ocular disorders may not be recognised without careful assessment and are frequently unidentified in children with complex needs. Although assessment may be more challenging than in other children, identifying these potential additional barriers to learning and development may be critical. There is a need to develop clearer guidelines, referral pathways and closer working between all professionals involved in the care of children with disability and visual disorders to improve our focus on the assessment of vision and outcomes for children with disability.
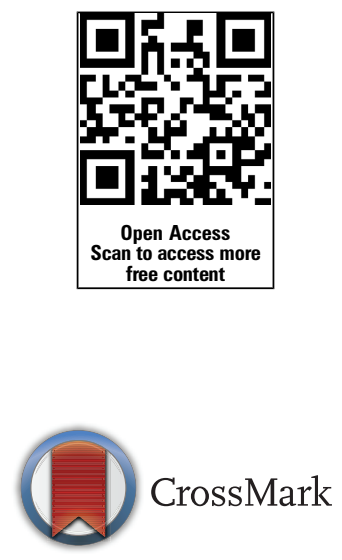

To cite: Salt A, Sargent J. Arch Dis Child

2014;99:1163-1168.

\section{INTRODUCTION}

Visual impairment (VI) is relatively rare among childhood disabilities, with a cumulative incidence of severe VI (SVI) in the general population of 6 per 10000 by 16 years of age; in over $75 \%$ of children, visual loss occurs in the context of significant non-ophthalmic impairments or disorders. ${ }^{1}$ However, in children with complex or multiple disabilities, visual and indeed ocular problems are relatively common but may be overlooked as the focus may be on other aspects of health or management. ${ }^{23}$

The higher prevalence of visual disorders in children with developmental disabilities is accounted for by the many underlying causes of their disability with prenatal and perinatal factors and acquired injury all of relevance. Therefore, visual disorders are particularly increased in children born preterm, children who have suffered brain damaging events with subsequent learning difficulty and/or cerebral palsy (CP) and children who have congenital cerebral anomalies or other genetic syndromes that may predispose to ocular anomalies. Children who have primary visual disorders may also be at risk of later disability. ${ }^{4}$

An overview of the various disorders that may affect the visual system in children with a disability is presented, with a focus on those at particularly high risk. Visual assessment can be challenging in this group of children and a practical approach to assessment will be outlined.

Definitions of VI and other terms are given in online supplementary appendix 1 .

\section{WHICH CHILDREN ARE AT MOST RISK OF VISUAL DIFFICULTY? \\ Children born preterm}

Children born preterm are at risk of brain injury, with periventricular leukomalacia (PVL), the most common brain lesion. Those who avoid major motor impairment are well known to be at risk of adverse developmental outcomes, including, for example, cognitive difficulty of variable degree, impairments in attention and executive function ${ }^{5} 6$. It is less commonly recognised that they are also at risk of visual or ocular abnormalities. VI in children born preterm has been reported in between 1\% and $3 \%$ with causes including cerebral VI and retinopathy of prematurity (ROP). ${ }^{7}$ Refractive errors have also been found to be four times more common in those born preterm (29.6\%) than those born at term $(7.8 \%)^{8}$ (table 1). These visual disorders result from both the 'premature exteriorisation' of the developing visual system and from the systemic complications of preterm birth. ${ }^{7}$

Holmström et $a l^{9}$ recently reported from a population-based follow-up study of 411 children born at $<27$ weeks' gestation, with only a minority having $\mathrm{CP}$ at 30 months' corrected age. Overall, a third had some type of eye or visual problem, most frequent in children previously treated for ROP (table 2).

Although hypermetropia is the most common refractive error in childhood, myopia is more common in those born preterm, occurring both in those with and without previous ROP. In those with strabismus, esotropia and exotropia are equally common, in contrast to full-term children in whom esotropia is three times as common as exotropia. $^{7}$

Difficulties with higher-order processing of visual information may also occur and some authors have particularly highlighted the occurrence of such difficulties in children with PVL. Hard et $a l^{16}$ reported poor visual perceptual skills in almost half of a group of 51 children born before 29 weeks' gestation, only $6 \%$ of whom had PVL. Pagliano et al ${ }^{17}$ studied 24 children with spastic diplegia and PVL, 15 born prematurely and 9 at term. Those born preterm had poorer visual perceptual skills, suggesting that the PVL was not the key factor, but some other consequence of prematurity.

\section{Children with $\mathrm{CP}$}

Premature birth and its sequelae are common precursors to $\mathrm{CP}$ and overlap exists between these two groups. Other causes of $\mathrm{CP}$, including term hypoxic ischaemic encephalopathy, early brain malformations and congenital or postnatal infections, will also contribute to visual outcomes.

Data from UK and European CP registers indicate that up to $11 \%$ of children with CP are found 
Table 1 Types of acuity measures used in children with disability

\begin{tabular}{|c|c|c|c|}
\hline Type of measure & Principle of test and materials & Administration/response & Examples \\
\hline $\begin{array}{l}\text { Resolution: of spatial detail, for example, } \\
\text { black and white lines }\end{array}$ & $\begin{array}{l}\text { 'Vanishing target' - target that is not resolved } \\
\text { 'blurs' to background } \\
\text { Child prefers to look at target that contains } \\
\text { visual contrast }\end{array}$ & $\begin{array}{l}\text { Child fixates target } \\
\text { Tester blind to location of target and makes } \\
\text { judgement of child's fixation } \\
\text { Naming or pointing are not required }\end{array}$ & $\begin{array}{l}\text { Keeler cards } \\
\text { Teller cards } \\
\text { Cardiff cards }\end{array}$ \\
\hline Recognition & $\begin{array}{l}\text { Some cognitive skill required-for example, } \\
\text { matching }\end{array}$ & $\begin{array}{l}\text { Child names or matches } \\
\text { Matching usually achieved through pointing }\end{array}$ & $\begin{array}{l}\text { Lea symbols } \\
\text { Kay pictures } \\
\text { Sonksen LogMAR test }\end{array}$ \\
\hline
\end{tabular}

to have SVI (acuity <6/60). ${ }^{12} 18$ A retrospective case series of 92 children with spastic quadriplegia from a single centre in Canada reported $20 \%$ with 'blindness ${ }^{19}$ (not further defined).

A higher incidence of visual difficulties is generally seen in those with more severe motor impairment. ${ }^{20-22}$ However, visual difficulties are neither restricted to a single neurological or aetiological subtype of CP nor to acuity loss. ${ }^{20} 2123$

Ocular disorders including refractive error, strabismus and minor ocular abnormalities, not associated with significantly reduced acuity, also increased ${ }^{13}$ (table 2).

Very marked abnormalities of eye movement have also been found in children with CP, some of whom may have been previously described as 'blind'. ${ }^{24}$ Lesser degrees of oculomotor difficulty affecting both smooth pursuit and saccades have been described in children with all distributions of $\mathrm{CP}^{26}$.

Children with CP can therefore be described as showing a range of neuro-ophthalmological abnormalities (reduced acuity, refractive errors, strabismus, oculomotor abnormalities and field alterations), which may be predictable according to the distribution of the motor impairment. ${ }^{26}$

Children with PVL have also been found to have visuoperceptual difficulties that were not explained by acuity or cognitive impairments. ${ }^{27} 28$ These included weakness in visual object recognition, visuospatial skills, visual memory and oculomotor control.

Impairments of visual attention in children with CP have been described using a variety of terms, including 'fixation impersistence', 'abnormal fixation', 'variable performance' and 'gaze dysfunction'. $22 \quad 2930$ A complex relationship between visual attention, visuoperceptual difficulties and eye movements may exist. Children with very severe attentional difficulties are at risk of being misdiagnosed as 'blind' as they may not be able to achieve or maintain fixation during vision testing.

\section{Visual outcomes following brain injury}

Visual difficulty occurring in the context of a normal ocular exam is now generally termed cerebral (previously cortical) visual impairment (CVI). A number of different definitions of CVI exist, ${ }^{31}$ but most make reference to three criteria, namely a normal ocular examination, reduced visual acuity or subnormal visual performance and evidence of damage to the posterior visual pathways. While definitions are being clarified, it may be helpful to consider CVI as a 'spectrum' condition, in which not all possible consequences may manifest in each individual child or at all ages, for example, some aspects of perceptual dysfunction can only be identified in school-aged children. ${ }^{27}$ It is also important to appreciate the other non-visual factors that can affect overall visual performance especially in very young children, such as cognitive or social impairment or positioning difficulties in children with severe movement difficulty.

Some children who experience brain injury show marked abnormalities of visual performance in the first year of life, which lessen over time. While improvement in visual function has been described as a characteristic of CVI, it is possible that

Table 2 Comparison of visual impairments in children with disability (as reported in some key studies)

\begin{tabular}{|c|c|c|c|c|c|c|}
\hline & $\begin{array}{l}\text { Intellectual disability } \\
\text { IQ }<80^{*} \\
\text { Nielsen }{ }^{3} 10 \\
\%\end{array}$ & $\begin{array}{l}\text { Intellectual } \\
\text { disability } \\
\text { IQ }<50 \\
\text { Nielsen } \\
\%\end{array}$ & $\begin{array}{l}\text { Down syndrome } \\
\text { (school age) Creavin } \\
\text { and Brown }{ }^{11} \\
\%\end{array}$ & $\begin{array}{l}\text { Cerebral } \\
\text { palsy } \\
\text { Surman } \\
\text { et } a l^{12} \\
\text { Woo et } a l^{13} \\
\%\end{array}$ & $\begin{array}{l}\text { Preterm birth } \\
0^{\prime} \text { Connor } \\
\text { et al } \\
\text { Holmström } \\
\%\end{array}$ & $\begin{array}{l}\text { General population } \\
\text { Rahi and Cable }{ }^{1} \\
\text { Nielsen } \\
\text { Donnelly et al }{ }^{15} \\
\%\end{array}$ \\
\hline Visual acuity (VA) $\leq 6 / 60$ & 3.8 & 22.4 & & & $1-3^{8}$ & \\
\hline VA $<6 / 60$ & & & & $\begin{array}{l}9-11^{12} \\
5^{13}\end{array}$ & $0.8^{9}$ & $0.06^{1}$ \\
\hline$V A \leq 6 / 18$ & 10.5 & 9 & - & - & $2.5^{8}(\leq 6 / 24)$ & $0.16^{14}$ \\
\hline$V A<6 / 18$ & & & & & & $0.13^{15}$ \\
\hline $\begin{array}{l}\text { All refractive errors } \\
\text { (hyperopia } \geq+2.0 \mathrm{D} \text { ) }\end{array}$ & 44 & & 55 & $60^{13}$ & $\begin{array}{l}19^{8} \\
\text { (<35 weeks) }\end{array}$ & $4.5^{14}$ \\
\hline Myopia & $11(<-0.5)$ & $16(<-0.5)$ & $13(<-0.75)$ & $46.6^{13}(\leq 1.5)$ & $10-18.9^{8}(<0)$ & $1.39^{15}(\leq 0.75)$ \\
\hline Hyperopia ( $\geq+2.0 \mathrm{D})$ & 24 & - & & $\begin{array}{l}10.2^{13} \\
(\geq+1.5)\end{array}$ & - & $0.13^{15}$ \\
\hline Hyperopia ( $\geq+3.0$ D) & 15.3 & 21.8 & 42 & & $4-6.6^{8}$ & $0.9^{14}$ \\
\hline Astigmatism (<-1.0 cyl D) & 20.6 & 34.7 & 37.5 & $20.5^{13}(\geq 3.0)$ & $13.7^{8}$ & $4.1-7.7^{14}(\geq 1.0) \mathrm{D}$ \\
\hline Strabismus & 27 & - & 25 & $59^{13}$ & $13.5-44^{89}$ & $4-7.5^{1415}$ \\
\hline
\end{tabular}


for some children this may simply reflect a slower than normal maturation of the visual system.

\section{Children with learning difficulty}

Several studies have reported an increased risk of VI in children with learning disability (LD). ${ }^{3} 1032$ One of the most comprehensive population-based studies of children with borderline to profound learning difficulty, aged 4-15 years, found that the prevalence of VI was as much as 10 times higher than that described in general population-based studies ${ }^{10}$ (table 2).

The most common aetiologies of VI in studies of children with additional learning difficulties were CVI, optic atrophy, retinal dystrophies and congenital nystagmus. ${ }^{10}$ This is in line with the most common disorders described in the general population of children with VI. ${ }^{1}$

Other more minor and potentially correctable visual disorders such as refractive disorders and strabismus also occur at higher frequency in children with LD (table 2$)^{14} 32$

In children with $\mathrm{LD}$, the prevalence of strabismus is most commonly reported to be between $21 \%$ and $27 \%$ (table 2) compared with up to $4 \%$ in typically developing children. ${ }^{15}$ Refractive errors and strabismus have also been found to be correlated with low IQ. ${ }^{14}$

Ophthalmological pathology has also been reported in $40 \%$ of patients with autism or related disorders, with $29 \%$ having significant refractive errors, $21 \%$ strabismus and $10 \%$ amblyopia. $^{33}$

\section{Down syndrome}

Trisomy 21 is one of the most common genetic disorders of childhood, and children with this disorder are at high risk of additional ocular disorders including refractive errors, reduced accommodation, strabismus, blepharitis, nasolacrimal duct problems, cataracts, congenital or acquired and keratoconus. ${ }^{11} 34$

Maturation of acuity is often slower than in typically developing children and many children have slightly reduced visual acuity even when refractive errors are appropriately corrected..$^{35}$ There is also a high prevalence of strabismus among children with Down syndrome, independent of refractive error ${ }^{36}$ (table 2).

Underaccommodation has also been found to be a substantial problem even when there is no, or a fully corrected, refractive error. This has important implications because near vision will be consistently out of focus for these children. Woodhouse has shown that children can benefit from provision of bifocal spectacles to compensate for poor accommodation. ${ }^{37}$

\section{Children with severe hearing impairment}

Congenital rubella syndrome was previously the most common cause of dual sensory impairment in UK children but is now rare. Other congenital infections due to other infectious agents may have similar consequences. ${ }^{38}$

CHARGE association, a genetic condition, is now the most common congenital cause of dual sensory impairment. ${ }^{38}$ VI arises from ocular coloboma and is variable in degree. In severe cases, the eye can be rudimentary or anophthalmic; however, involvement is often asymmetrical. Retinal coloboma will also affect the visual field and will lead to severe acuity impairment if the macula or optic disc is affected. There is also an increased risk of retinal detachment and of corneal injury if there is incomplete eye closure.

Children with dual sensory impairment of any cause should undergo very careful evaluation of each sense.

\section{Box 1 Developmental impact of visual impairment}

Visual impairment affects the development of:

- spatial awareness, posture and movement skills

- use of hands and fine movement coordination

- early concept development, for example, object permanence

- locating sound in space

- understanding of the meaning of words and therefore speech and language development

- social interaction and communication

- self-care skills.

\section{Primary visual impairment leading to disability}

Vision integrates all other senses and therefore it is not surprising that SVI is known to constrain all areas of development in the early years of life. This is directly related to the level of vision loss (box 1). ${ }^{4}$

Development can be delayed by as much as 2 years in the first years of life and therefore specific developmental norms are available for children who are 'blind' and 'partially sighted'. These delays can be overcome by the time children reach school age.

However, in children with profound VI (awareness of light or light-reflecting objects only) research has found that

\section{Box 2 Assessment of ocular health and function} (refraction, ocular movements, accommodation) and vision assessment

Current concerns and parent descriptions of everyday use of vision

Ocular exam

- observation for structural anomalies external, anterior and posterior segments of the eye

- observation for strabismus/squint

- eye movements-smooth pursuit and saccades

- refraction-eye clinic-optometrist

- electrophysiological: electroretinogram and visual evoked potential if indicated-eye clinic.

Assessment of vision

Detection vision

- If vision is severely reduced, aim to quantify with near detection scale. $^{40}$

Fixation

- quality: sustained, brief, uncertain

- fixation shifts: to objects presented

Visual recognition-(also elicited in history)

- faces

- objects

- pictures

Visual acuity

- behavioural measures:

- resolution acuity-measured by preferential looking

- recognition acuity-measured by matching or naming symbols or letters

Visual fields

- confrontation/modified distraction method

- formal perimetry possible in older children-eye clinic 
approximately $30 \%$ of children are at risk of stasis or regression in cognitive development during the second year of life. ${ }^{4}$ Disordered social communication is most prominent in this group and the high level of autistic spectrum disorder in children who are blind is increasingly well recognised. This outcome is found even in children who have a primary visual disorder with no other obvious risk factors for brain vulnerability. It may be that there are as yet unknown genetic factors that contribute, but it seems likely that sensory deprivation plays a significant role in this serious developmental disorder.

\section{Approach to identification of ocular or visual difficulty}

Paediatric assessment of a child with disability should always include an ocular and visual assessment. Box 2 outlines a systematic approach. Potential visual difficulties can be identified through careful history taking (table 3), observation for ocular anomalies, eye movement difficulty (squint, nystagmus) or atypical visual performance. Assessment of fixing and following and near detection can be carried out in the clinic. Acuity can also be measured if tools are available (table 1 ).

Assessment of the child with disability should follow the same principles as that of any child, but adaptations may be necessary to take account of the child's developmental age and capacity to cooperate with more formal assessment. Therefore, knowledge of a child's developmental level is essential.

Children with severe physical disability may require adaptations to test administration and the preceding history should elicit descriptions of their usual response methods. A child must be comfortable and adequately positioned if optimal responses are to be elicited. Multidisciplinary assessment is helpful in building up a detailed picture of the impact of non-visual factors on the child's overall visual profile. An important principle of assessment is to gather information and objective observations before considering all possible explanations, both visual and non-visual, for the information gathered.

Any identified difficulty should prompt early referral to the eye clinic for more detailed ophthalmological examination including refraction, behavioural observations and acuity measurement with electrophysiology (measuring the integrity of the retina and visual pathways) where indicated. MRI may also assist in understanding the potential structural correlates of visual function as well as the pattern of additional impairments or antecedent medical history.

If SVI is identified, a referral to the local Specialist Teaching team for children with VI should also be made. It is not necessary to wait for diagnostic confirmation if paediatric assessment indicates that severe visual difficulty is present.

\section{History taking}

Assessment always begins here and incorporates exploration of the current questions and concerns as well as detailed descriptions of the child's current visual skills. In some situations, the responses of children with additional disabilities may be interpreted according to hope, and beliefs about skills that may be based on an incomplete understanding of information received. For example, parents may previously have been told that their child's eyes are 'normal' leading to a belief that this guarantees normal vision. Careful enquiry as to whether the child's visual responses are predictable or variable and possibly dependent on other sensory modalities is vital, for example, is the child seeing or relying on hearing to respond to the stimulus.

\section{Questionnaire approaches}

To overcome some of the potential challenges of visual assessment in children with severe movement or other developmental difficulties, some authors have explored the usefulness of structured questionnaires. McCulloch et $a l^{41}$ developed a questionnaire to clarify visual skills in neurologically impaired children likely to have profound VI. Ferziger et $a l^{42}$ developed a questionnaire designed to document evidence of basic visual skills in children with multiple disabilities. Questionnaires to elicit possible manifestations of CVI have also been developed for use with children whose acuity is $6 / 60$ or better. ${ }^{43}$ However, it is important to appreciate that the role of some tools is to identify children who would benefit from further detailed history taking and assessment ${ }^{44}$ and that some 'screening' questions may yield false positives ${ }^{45}$ since some reported responses may be explained by other aspects of the child's disability.

\section{Outcomes of assessment}

Paediatricians are well placed to explain the consequences of any ocular abnormality or VI described by the ophthalmologist. For example, spectacles may be prescribed to correct refractive

Table 3 Parent history: current visual skills

\begin{tabular}{|c|c|}
\hline $\begin{array}{l}\text { Detection (knows something is there even if not what it is-depends on acuity) } \\
\text { Do you think she/he sees normally? Why/why not? } \\
\text { Does she/he look at your face? Up to what distance? } \\
\text { Does she/he follow as you walk away/as a toy is moved? } \\
\text { What size object/at what distance can she/he detect visually? } \\
\text { Does she/he try to peer closely at things? }\end{array}$ & $\begin{array}{l}\text { Considerations } \\
\text { Elicit a description of the child's response to each potential visual task. } \\
\text { For example, fixation or orientation/reaching/naming } \\
\text { Could response be dependent on any other clues including sound? }\end{array}$ \\
\hline $\begin{array}{l}\text { Children with additional difficulties } \\
\text { Does she/he ever stare at lights? } \\
\text { Does she/he often turn head or eyes in one particular direction? Are there any } \\
\text { movement difficulties that could explain this?* } \\
\text { Does she/he show any difficulty with steady looking or seem to need more time } \\
\text { than other children to look at something? } \\
\text { Can she/he look steadily at an object so that you know for sure what s/he is } \\
\text { looking at? } \\
\text { If your child's eyes show frequent movements, } † \text { how often are you sure that } \\
\text { these movements are part of 'active looking'? } \\
\text { Can she/he look at and reach for something at the same time? } \\
\text { Does she/he make eye contact that makes you feel looked at? }\end{array}$ & $\begin{array}{l}\text { Recognition (ability to know what target is through visual information alone, may depend } \\
\text { on detection of visual detail and on cognitive skills) } \\
\text { Does she/he recognise your face (without voice)? } \\
\text { Does she/he return a silent smile? } \\
\text { Does she/he recognise objects through vision alone? Or needs additional cues? } \\
\text { What objects does she/he recognise? How far away? } \\
\text { Does she/he look at pictures? } \\
\text { Can she/he recognise simple unfamiliar pictures, or pick out any detail from a 'busy' } \\
\text { picture? } \\
\text { Does she/he watch TV? Seated at what distance? Remains visually oriented even when } \\
\text { sound is muted? }\end{array}$ \\
\hline
\end{tabular}

*Does the child have a persistent asymmetric tonic neck reflex? Is there evidence that a particular head position is associated with minimisation of nystagmus? Can we be confident that the eye or head turning is definitely vision related or could they be spontaneous movements that are not in response to any stimulus?

tEnsure parents do not mean nystagmus, which is a wobbly movement or fast to and fro flickering. 
error, though parents and professionals may need to understand that some children have additional, uncorrectable acuity reduction. Minor acuity reduction can be addressed through adaptation of visual material and advice about positioning within the classroom. For children with severe movement difficulty for whom vision can function as an important 'response mode', ${ }^{46}$ the functional consequences of combined abnormalities of acuity, eye movement and attentional difficulties may best be understood by pooling all observations from the paediatric, therapy and educational teams.

\section{Service provision}

To meet the visual needs of children with disability, stronger links are needed between child development and community paediatric services, ophthalmology and specialist education services for children with VI. Some districts have a team with a special interest in vision who provide joint assessments and support links between all these services. The team may comprise a paediatrician, orthoptist, ophthalmologist (or have close links with a named ophthalmologist) and a qualified teacher for children with VI.

Some tertiary centres provide specialist assessment for children with VI. They can address questions that may be more challenging for local teams such as developmental questions in children with profound VI. Clinical judgements about this rare group of children require a breadth of experience that cannot usually be gained at secondary level.

\section{Current practice: surveillance for children with disability at increased risk of ocular and visual disorders}

Hall and Elliman ${ }^{47}$ state the need for visual assessment of children with neurological impairment/CP, but in practice, assessment may be haphazard and abnormalities, which may in some children be severe, can be missed. ${ }^{2} 4849$

Studies of children with special needs have established that there are significant unmet visual needs in a high proportion of children, with one study reporting a fifth with SVI (legal blindness) who were undiagnosed. ${ }^{3}$ Woodhouse recently reported that half of a cohort of children attending special schools had refractive errors warranting new or first-time spectacle prescription. $^{2}$ These studies highlight the high level of potential unmet visual need in children with disabilities.

Although the full range of ocular and visual outcomes for children with learning difficulty, $\mathrm{CP}$ and other children with disability or at high risk of poor visual outcomes is well described in the literature, there are few agreed guidelines for routine assessment. School-based examination of children in specialist education has been recommended, ${ }^{2}$ but local practice varies widely in the UK. For children with Down syndrome, clear guidelines have been published recommending monitoring for the onset of significant refractive errors and for strabismus regularly throughout early childhood. However, adherence to recommendations is variable. ${ }^{5051}$

\section{How can practice be improved?}

Closer working between professionals involved primarily in ocular and vision health and those working with children with disability would facilitate adherence to current guidelines and support identification of VI and potentially correctable vision difficulties in children who are known to be at high risk. In some child development teams (CDT), closer working is facilitated by an orthoptist working with the team. However, currently less than one-fifth of CDT have an orthoptist within the CDT (J Parr, personal communication, 2014). ${ }^{52}$
Guidelines need to include routine ophthalmological assessment for children with severe hearing impairment and for those with severe physical disability who are highly dependent on active use of vision to support their communication and learning. ${ }^{38}$ In addition, children with primary VI are at high risk of developing subsequent additional disability and therefore need intensive support and monitoring of development. The presence of even limited form vision appears protective, therefore visual promotion and support for families as early as possible is critical. $^{4}$

\section{Future developments}

Vision is arguably the most important sensory modality underpinning child development and multiple professionals currently contribute to assessment of ocular structure and function and management of pathology. Assessment of vision itself can somehow be overlooked or at least not fully reported particularly in children with established disability. By contrast, children with suspected hearing impairment undergo dedicated and often repeated assessment of hearing by professionals whose specialism is audiology. While it may not be practical or even necessary to envisage a new speciality of 'visuology', the multidisciplinary team, with the paediatrician at the centre, can nevertheless work more closely together to confirm the importance of detailed visual assessment that 'measures' acuity and assesses other vital aspects of ocular function and visual skill, and also provides practical, tailored guidance for the individual child.

Contributors AS and JS contributed equally to the literature review, writing and editing of the article.

\section{Competing interests None.}

Provenance and peer review Commissioned; externally peer reviewed.

Open Access This is an Open Access article distributed in accordance with the Creative Commons Attribution Non Commercial (CC BY-NC 4.0) license, which permits others to distribute, remix, adapt, build upon this work non-commercially, and license their derivative works on different terms, provided the original work is properly cited and the use is non-commercial. See: http://creativecommons.org/ licenses/by-nc/4.0/

\section{REFERENCES}

1 Rahi JS, Cable N. Severe visual impairment and blindness in children in the UK. Lancet 2003;362:1359-65.

2 Woodhouse JM, Davies N, McAvinchey A, et al. Ocular and visual status among children in special schools in Wales: the burden of unrecognised visual impairment. Arch Dis Child 2013;99:500-4.

3 Welinder LG, Baggesen KL. Visual abilities of students with severe developmental delay in special needs education - a vision screening project in Northern Jutland, Denmark. Acta Ophthalmol 2012;90:721-6.

4 Sonksen PM, Dale N. Visual impairment in infancy: impact on neurodevelopmental and neurobiological processes. Dev Med Child Neurol 2002;44:782-91.

5 Johnson S, Hennessy E, Smith R, et al. Academic attainment and special educational needs in extremely preterm children at 11 yrs of age: the EPICURE study. Arch Dis Child Fetal Neonatal Ed 2009;94:F283-9.

6 O'Shea TM, Downey LC, Kuban KKC. Extreme prematurity and attention deficit: epidemiology and prevention. Front Hum Neurosci 2013;7:578.

7 O'Connor AR, Wilson CM, Fielder AR. Ophthalmological problems associated with preterm birth. Eye 2007;21:1254-60.

8 O'Connor AR, Stephenson TJ, Johnson A, et al. Visual function in low birthweight children. Br J Ophthalmol 2004;88:1149-53.

9 Holmström GE, Källen K, Hellström A, et al. Ophthalmologic outcome at 30 months' corrected age of a prospective Swedish cohort of children born before 27 weeks of gestation the extremely preterm infants in Sweden study. JAMA Ophthalmol. 2014;132:182-9.

10 Nielsen LS, Skov L, Jensen H. Visual dysfunctions and ocular disorders in children with developmental delay. I. prevalence, diagnoses and aetiology of visual impairment. Acta Ophthalmol Scand 2007;85:149-56.

11 Creavin AL, Brown RD. Ophthalmic abnormalities in children with Down syndrome. J Pediatr Ophthalmol Strab 2009;46:76-82. 
12 Surman G, Bonellie S, Chalmers J, et al. UKCP: a collaborative network of CP registers in the UK. J Public Health 2006;28:148-56.

13 Woo SJ, Ahn J, Park MS, et al. Ocular findings in cerebral palsy patients undergoing orthopedic surgery. Optom Vis Sci 2011;88:1520-3.

14 Nielsen LS, Skov L, Jensen H. Visual dysfunctions and ocular disorders in children with developmental delay. II. Aspects of refractive errors, strabismus and contrast sensitivity. Acta Ophthalmol Scand 2007;85:419-26.

15 Donnelly UM, Stewart NM, Hollinger M. Prevalence and outcomes of childhood visual disorders. Ophthalmic Epidemiol 2005;12:243-50.

16 Hard AL, Niklasson A, Svensson E, et al. Visual function in school-aged children born before 29 weeks of gestation: a population-based study. Dev Med Child Neurol 2000;42:100-5.

17 Pagliano E, Fedrizzi E, Erbetta A, et al. Cognitive profiles and visuoperceptual abilities in preterm and term spastic diplegic children with periventricular leukomalacia. J Child Neurol 2007;22:282-8.

18 Surveillance of Cerebral Palsy in Europe. Prevalence and characteristics of children with cerebral palsy in Europe Surveillance of Cerebral Palsy in Europe (SCPE). Dev Med Child Neurol 2002;44:633-40.

19 Venkateswaran S, Shevell MI. Comorbidities and clinical determinants of outcome in children with spastic quadriplegic cerebral palsy. Dev Med Child Neurol 2008;50:216-22.

20 Dufresne D, Dagenais L, Shevell, et al. EPACQ Consortium. Spectrum of visual disorders in a population-based cerebral palsy cohort. Pediatr Neurol 2014;50:324-8.

21 Shevell MI, Dagenais L, Hall, et al. EPACQ Consortium. Comorbidities in cerebral palsy and their relationship to neurologic subtype and GMFCS level. Neurology 2009;72:2090-6.

22 Ghasia F, Brunstrom J, Gordon M, et al. Frequency and severity of visual sensory and motor deficits in children with cerebral palsy: gross motor function classification scale. Invest Ophthalmol Vis Sci 2008:49:572-80.

23 Himmelmann K, Hagberg G, Uvebrant P. The changing panorama of cerebral palsy in Sweden. X. Prevalence and origin in the birth-year period 1999-2002. Acta Paediatr 2010;99:1337-43.

24 Jan JE, Lyons CJ, Heavenn RKB, et al. Visual Impairment due to a dyskinetic eye movement disorder in children with dyskinetic cerebral palsy. Dev Med Child Neurol 2001;43:108-12.

25 Salati R, Borgatti R, Giammari G, et al. Oculomotor dysfunction in cerebral visual impairment following perinatal hypoxia. Dev Med Child Neurol 2002;44:542-50.

26 Fazzi E, Signorini SG, La Piana R, et al. Neuro-ophthalmological disorders in cerebral palsy: ophthalmological, oculomotor, and visual aspects. Dev Med Child Neurol 2012;54:730-6.

27 Fazzi E, Bova S, Giovenzana A, et al. Cognitive visual dysfunctions in preterm children with periventricular leukomalacia. Dev Med Child Neurol 2009;51:974-81.

28 Fedrizzi E, Anderloni A, Bono R, et al. Eye-movement disorders and visual-perceptual impairment in diplegic children born preterm: a clinical evaluation. Dev Med Child Neurol 1998;40:682-8.

29 Hood B, Atkinson J. Sensory Visual Loss and Cognitive deficits in the selective attentional system of normal infants and neurologically impaired children. Dev Med Child Neurol 1990;32:1067-77.

30 Guzetta A, Cioni G, Cowan F, et al. Visual disorders in children with brain lesions: Visual impairment associated with cerebral palsy. Eur J Paediatr Neurol 2001;5:115-17.

31 Boot FH, Pel JJ, van der Steen J, et al. Cerebral Visual Impairment: which perceptive visual dysfunctions can be expected in children with brain damage? A systematic review. Res Dev Disabil 2010;31:1149-59.
32 Woodruff ME. Prevalence of visual and ocular anomalies in 168 non-institutionalized mentally retarded children. Can J Public Health 1977;68:225-32.

33 Ikeda J, Davitt BV, Ultmann M, et al. Incidence of ophthalmic disorders in children with autism. J Autism Dev Disord 2013;43:1447-51.

34 Haugen $\mathrm{OH}$, Hovding $\mathrm{G}$, Lundstrom I. Refractive development in children with Down's syndrome: a population-based longitudinal study. Br J Ophthalmol 2001;85:714-19.

35 Woodhouse JM, Pakeman VH, Saunders KJ, et al. Visual acuity and accommodation in infants and young children with Down's syndrome. J Intellect Disabil Res 1996; 40:49-55.

36 Cregg M, Woodhouse JM, Pakeham VH, et al. Development of refractive error and strabismus in children with Down syndrome. Invest Ophthalmol Vis Sci 2003:44:1023-30.

37 Cregg M, Woodhouse JM, Pakeham VH, et al. Accommodation and refractive error in children with down syndrome: cross-sectional and longitudinal studies. Invest Ophthalmol Vis Sci 2001;42:55-63.

38 Armitage IM, Burke JP, Buffin JT. Visual impairment in severe and profound sensorineural deafness. Arch Dis Child 1995;73:53-6.

39 Reynell J, Zinkin P. Reynell-Zinkin Developmental Scale for Young Visually Handicapped Children Part 1. Mental Development. Windsor. Berkshire. NFER. 1979.

40 Sonksen PM, Petrie A, Drew KJ. Promotion of visual development in severely visually impaired babies; evaluation of a developmentally based programme. Dev Med Child Neurol 1991;33:320-35.

41 McCulloch DL, Mackie RT, Dutton GN, et al. A visual skills inventory for children with neurological impairments. Dev Med Child Neurol 2007;49: 757-63.

42 Ferziger NB, Nemet $P$, Brezner A. A visual skills inventory for children with neurological impairments. Dev Med Child Neurol 2011;53:422-8.

43 Houliston MJ, Taguri AH, Dutton GN, et al. Evidence of cognitive visual problems in children with hydrocephalus: a structured clinical history taking strategy. Dev Med Child Neurol 1999;41:298-306.

44 Dutton GN. Structured history taking to characterize visual dysfunction and plan optimal habilitation for children with cerebral visual impairment. Dev Med Child Neurol 2011;53:390.

45 Van Genderen M, Dekker M, Pilon F, et al. Diagnosing cerebral visual impairment in children with good visual acuity. Strabismus 2012;20:78-83.

46 Sargent J, Clarke M, Price $\mathrm{K}$, et al. Use of eye-pointing by children with cerebral palsy: what are we looking at? Int J Lang Comm Dis 2013;48: 477-85.

47 Hall DMB, Elliman D. Screening for vision defects. In: Hall DMB, Elliman D, eds Health for all children. Oxford University Press, 2006:226-37.

$48 \mathrm{O}^{\prime}$ Connor A, Fielder A. Visual outcomes and perinatal adversity. Semin Fetal Neonatal Med 2007;12:408-14.

49 Das M, Spowart K, Crossley S, et al. Evidence that children with special needs all require visual assessment. Arch Dis Child 2010;95:888-92.

50 Creavin AL. Ophthalmic assessment of children with Down syndrome: is England doing its bit? Strabismus 2010;18:142-5.

51 http://www.dsmig.org.uk

52 Parr JR, Jolleff N, Gray L, et al. Twenty years of research shows UK child development team provision still varies widely for children with disability. Child Care Health Dev 2013;39:903-7. 